\begin{tabular}{|l|l|}
\hline Title: & $\begin{array}{l}\text { Concrete shells - Towards efficient structures: Construction of an ellipsoidal } \\
\text { concrete shell in Switzerland }\end{array}$ \\
\hline Authors: & Muttoni A., Lurati F., Fernández Ruiz M. \\
\hline Published in: & Structural Concrete \\
\hline DOI & $10.1002 /$ suco.201200058/pdf \\
\hline Year of publication: & 2013 \\
\hline Type of publication: & Peer reviewed journal article \\
\hline
\end{tabular}

Please quote as:

Muttoni A., Lurati F., Fernández Ruiz M., Concrete shells - Towards efficient structures: Construction of an ellipsoidal concrete shell in Switzerland, Structural Concrete, 2013. 


\section{Concrete shells - towards efficient structures: construction of an ellipsoidal concrete shell in Switzerland}

\begin{abstract}
Concrete shells have been widely used in the past as economical and suitable solutions for a number of structures such as roofs, silos, cooling towers and offshore platforms. Taking advantage of their single or double curvature, bending moments and shear forces are limited, and the structures develop mostly membrane (in-plane) forces, allowing them to span large distances with limited thicknesses (typically just a few centimetres). In recent decades, advances in numerical modelling, formwork erection and concrete technology have opened up a new set of possibilities for the use of concrete shells. This paper describes the design and construction of a shell in the form of an ellipsoid $(93 \times 52 \times 22 \mathrm{~m})$ and with thickness varying between 100 and $120 \mathrm{~mm}$. The shell was built using sprayed concrete and also ordinary concrete in some regions. A number of tailored solutions were also adopted, such as post-tensioning, addition of fibres and shear studs, to ensure satisfactory performance at both the serviceability and ultimate limit states.
\end{abstract}

Keywords: shell, concrete structure, design, sprayed concrete, fibre-reinforced concrete, architecture

\section{Introduction}

\section{Masonry arches and vaults}

The history of masonry arches and vaults is rich and embraces a number of building traditions. Detailed summaries and analyses can be consulted elsewhere [1-5]. Masonry arches were most probably the first structures invented by mankind to span significant distances across rivers or valleys. These structures, which might have been inspired by natural shapes, appeared as early as the 2nd millennium BC in Mesopotamia. They are composed of a set of prepared stones (voussoirs) arranged side by side in direct contact or with intermediate mortar. Taking advantage of the shape of the arch, external actions (gravity-induced forces and imposed loads) are carried by the compression forces that develop internally and at the interfaces between the voussoirs (and sometimes through the spandrel walls and filling at the extrados of the masonry works). The line defining the theoretical resultant of the compression forces equilibrating the external actions

\footnotetext{
* Corresponding author: miguel.fernandezruiz@mfic.ch
}

Submitted for review: 8 December 2012

Accepted for publication: 12 December 2012 is usually called the "thrust line" (comprising its associated thickness referring to the material strength) and needs to remain inside the masonry since no tensile stresses are acceptable at the joints of such constructions [5]. The shape of the arch is thus decisive. Shapes where the thrust line does not remain inside the masonry are not in equilibrium with the external actions and lead to the collapse of the structure.

Vaults are double-curvature surfaces assembled from masonry voussoirs or bricks. They have traditionally been used as roofs or to cover underground constructions. As for masonry arches, vaults need to develop the thrust surface within the masonry work. However, loads can be carried in more than one direction due to the double curvature of the vaults. For classical dome shapes, with spherical soffits, the pressure surface can be kept within the masonry by significantly increasing its thickness in selected zones (e.g. Pantheon dome, Rome). In these cases the vaults exert a horizontal thrust at the bottom supports. Another possibility is to provide the vault with tangential tensile forces, keeping the pressure surface within the masonry. St. Peter's basilica (Vatican City) was strengthened in the mid-18th century with four iron chains serving as a tension ring after large cracks in the dome were discovered [5].

\section{Reinforced concrete shells}

The problems observed for masonry works, and in particular for vaults (adequacy of the form for the actions leading to significant thicknesses), can be mostly solved with the addition of reinforcement, whose tensile forces can deviate the thrust surface, allowing it to lie within the concrete. As a consequence, reinforced double-curvature structures develop mostly membrane forces (in-plane axial and shearing forces) and very limited bending and out-ofplane shear forces. As a consequence, the required thickness can be significantly reduced, leading to double-curvature thin concrete shells.

Following this principle of membrane behaviour, the first concrete shells were built expressing this potential in a clear manner [6]. Designers in Europe (F. Dischinger, E. Torroja, R. Maillart) and America (A. Tedesko) experienced the advantages of such constructions with thicknesses as low as 30-40 mm. These works, built mainly between 1910 and 1940, typically used shapes defined by analytical expressions (such as sections of spheres, cylin- 
ders or hyperbolic paraboloids). They included stringers in the edges to ensure membrane behaviour as perfectly as possible. The difficulties encountered in the analytical treatment of thin shells explains the rather limited number of shapes used during this period and the low number of designers using them. Following this period, interesting new developments took place between 1940 and 1970 in America, instigated by the Spanish architect F. Candela and the Uruguayan engineer $E$. Dieste (the latter also involved with the development of masonry shells). Their approach consisted of performing analyses that were as simple as possible (Candela particularly) and combining different sections of previous shapes, preferring mostly hyperbolic paraboloids due to their plastic qualities and ease of construction. Their approach led to a larger and richer variety of forms. In Switzerland, H. Isler [7, 8], too, built an impressive number of unusual shells between the 1960s and 1980s whose shape was obtained and optimized by different mechanical analogies (pneumatic, gravity-shaped membranes, etc.). It should be noted that, actually, the different experiences with concrete shells were mostly linked to the skills of their designers rather than to a continuous evolution in concrete shell design.

In the 1980s and 1990s, concrete shells were seldom used as a consequence of the large number of man-hours required for building formwork and placing reinforcement with respect to the material costs, which typically gave priority to other structural solutions. In recent years, the situation has changed somewhat. The possibilities offered by new types of concrete (as fibre-reinforced concrete), reinforcement, numerical cutting of formwork and its positioning on the construction site as well as the new possibilities available for the analysis of these structures (related mostly to computer software) have allowed the development of a new approach to shells, with more freedom in the choice of shape. Nevertheless, an understanding of the role of double curvature, the load-carrying mechanisms and the governing limit states of these structures still remains essential to the design of shells. This is particularly relevant with respect to the analysis of the buckling behaviour of these structures. A state-of-the-art review of this topic was published in 1979 [9] by the International Association for Shell \& Spatial Structures, providing guidance on such design. However, research is still being performed in this area $[10,11]$ and remains necessary.

In the following, the most significant aspects of the design and construction for concrete shells will be discussed with reference to a shell built recently in Switzerland, a project in which the authors of this paper were involved.

\section{Design of a concrete shell for covering a mall at Chiasso, Switzerland}

\section{Why a concrete shell?}

An ellipsoid-shaped roof was planned to cover a new mall to be constructed at Chiasso, Switzerland. This roof satisfied the requirements of the client in terms of usability, architectural needs and image. The thickness of the ellipsoid was decisive since it directly influenced the amount of floor area that could be let, see Fig. 1a. Solutions were
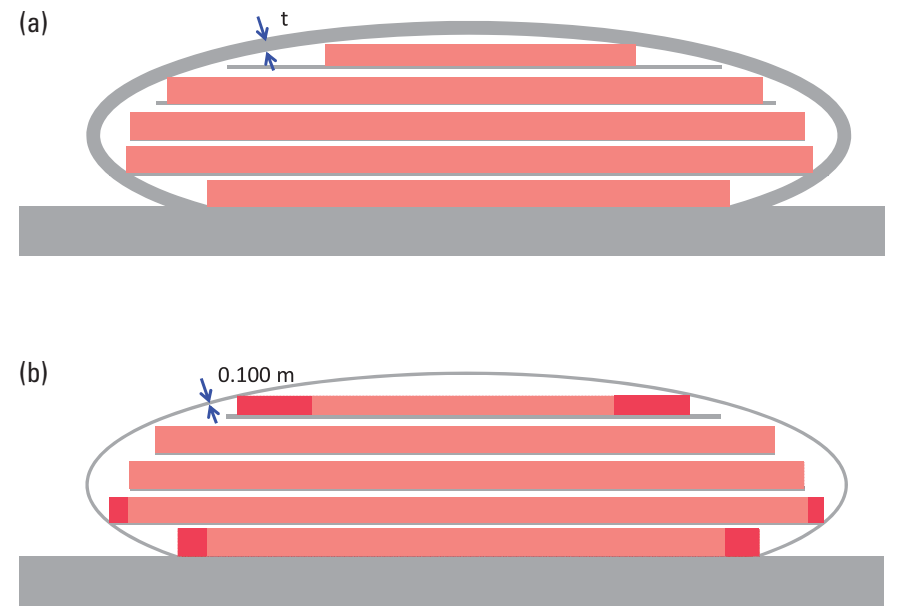

Fig. 1. How the thickness of the roof influences the lettable floor area: (a) thick roof, and (b) thin concrete shell

investigated using timber and steel linear elements. Local buckling, however, was the governing factor for these solutions, requiring significant thicknesses in the most critical parts. This led to uneconomical solutions for the client, with significant reductions in the lettable floor area. By contrast, a concrete shell was shown to be a suitable solution. Its thickness was only $100 \mathrm{~mm}$ in the critical regions influencing the lettable floor area. This allowed the client to have sufficient space available and optimized the cost of the mall (Fig. 1b).

\section{Geometry and main properties of shell}

The ellipsoid shell has axis dimensions of $92.8 \mathrm{~m}$ (major axis) and $51.8 \mathrm{~m}$ (minor axis) and is $22.5 \mathrm{~m}$ high. The ellipsoid is cut by a horizontal plane and is supported on a concrete basement composed of transverse walls, leading to a total height for the shell of $18.24 \mathrm{~m}$, see Fig. 2. The thickness of the shell varied. A value of $100 \mathrm{~mm}$ was selected as the default thickness. This was governed by constructive issues (minimum thickness considering reinforcement cover necessary) and also ensured adequate safety against buckling.

Four layers of reinforcement were provided, two at the intrados and two at the extrados of the shell. The reinforcement layers were oriented following the radial (meridian) and tangential (parallel) directions. This was selected as the most effective layout for structural reasons. The four-layer arrangement was needed to control the bending moments and shear forces that develop at the basement connection, near the prestressed zone, and for connecting to the steel structure at the zenith opening (Fig. 2). Bending moments and shear forces in other regions were very limited. Four reinforcement layers were nevertheless arranged in all regions for constructional reasons, to ensure suitable crack control (which may appear depending on the load cases) and to ensure adequate safety against buckling of the structure.

In addition to the ordinary reinforcement, 35 posttensioned tendons (0.6 inch monostrand tendons) were arranged near the equator of the shell (from level $+5.50 \mathrm{~m}$ to level $+12.60 \mathrm{~m}$, see Fig. 1) to carry membrane tension in the horizontal direction. (They also presented a limited di- 
(a)

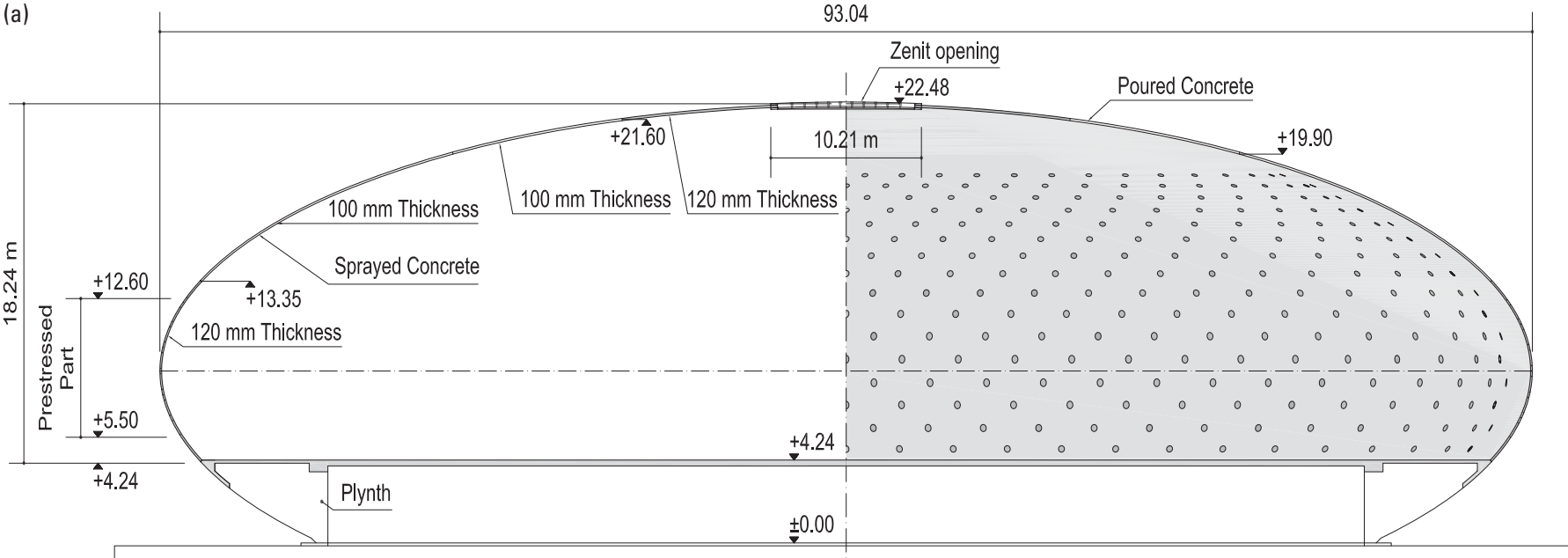

(b)

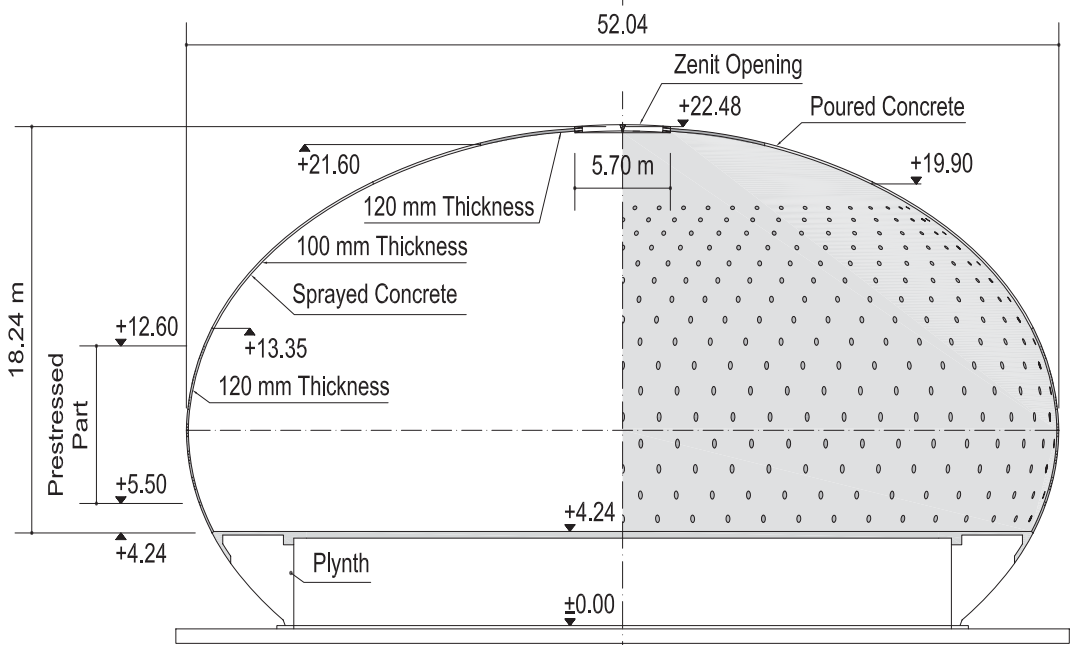

Fig. 2. Main geometrical dimensions: (a) section along major axis, (b) section along minor axis

mension for the plastic duct, thus minimizing the disturbance in the compression field developing through the shell $[12,13]$.$) The thickness of the shell was increased$ to $120 \mathrm{~mm}$ in this region (between levels $+4.24 \mathrm{~m}$ and $+13.35 \mathrm{~m})$.

At the level of the connection to the concrete basement (between levels $+4.24 \mathrm{~m}$ and $+5.14 \mathrm{~m}$ ), shear studs were also provided to ensure adequate shear strength and deformation capacity in this region (subjected to parasitic shear forces and bending moments).

The thickness of the shell was also $120 \mathrm{~mm}$ from level $+21.60 \mathrm{~m}$ to the zenith opening. In the top part, the increased thickness allowed the concrete shell to be linked to a steel structure at the zenith opening $(10.21 \times 5.70 \mathrm{~m})$; this allows daylight to reach the inside of the mall. In addition, between levels $+4.81 \mathrm{~m}$ and $+18.78 \mathrm{~m}$, there are several circular openings ( $0.40 \mathrm{~m}$ dia.), see Fig. 2.

\section{Concrete properties}

The structure was cast using sprayed concrete from level $+4.24 \mathrm{~m}$ to level $+19.90 \mathrm{~m}$. This allowed conventional (one-sided) formwork to be used for the entire shell. Where the slope was sufficiently limited $\left(<20^{\circ}\right.$, from level +19.90 m to level $+22.48 \mathrm{~m}$ ), concrete was poured conventionally. For both concrete types, a characteristic compressive strength $f_{c k}$ of $30 \mathrm{MPa}$ at 28 days was specified.
Hooked metallic steel fibres $\left(30 \mathrm{~kg} / \mathrm{m}^{3}\right)$ were used in the sprayed concrete region between level $+4.24 \mathrm{~m}$ and level $+13.36 \mathrm{~m}$. The fibres have a length of $30 \mathrm{~mm}$ and a length-to-diameter ratio of 80 . The fibres were arranged to enhance crack control (in the post-tensioned region) and to improve the ductility of concrete under high normal and shear forces (at the junction with the basement). The sprayed concrete contained $300 \mathrm{~kg} / \mathrm{m}^{3}$ of cement and $25 \mathrm{~kg} / \mathrm{m}^{3}$ of lean lime (to enhance the workability of the concrete). The aggregate sizes between 0 and $4 \mathrm{~mm}$ accounted for $70 \%$ of the total, the rest ranging between 4 and $8 \mathrm{~mm}$. Addition of water was performed at the spraying gun.

\section{Design aspects}

Apart from some aspects that were governed by constructional issues (e.g. shell thickness, as explained previously), the design of the shell and its reinforcement was governed by three structural aspects: the membrane (in-plane) inner forces in the shell, the second-order effects and the nonmembrane (parasitic) bending and shear forces at the junction with the concrete basement. The structure was modelled using a 3D finite element model (using the commercial program ANSYS) capable of performing linear and non-linear analyses. A comparison of the software re- 


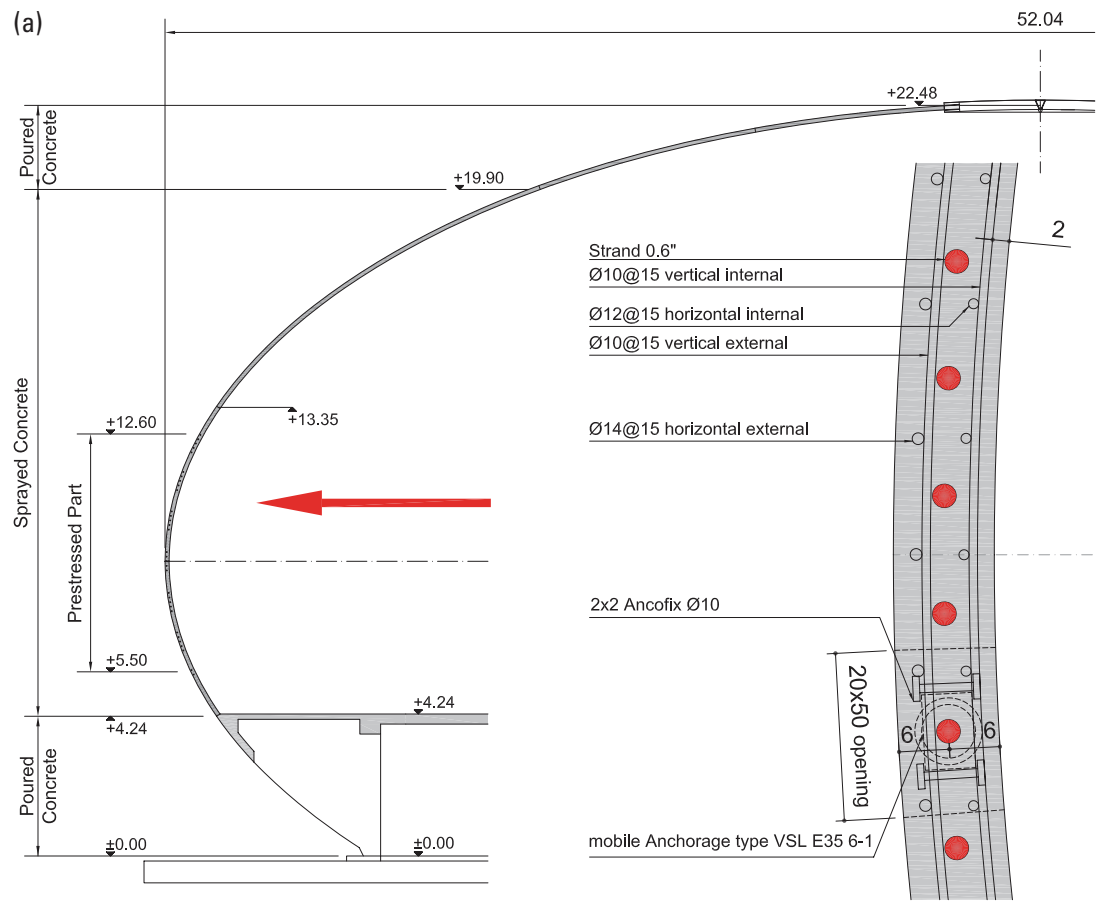

(b)

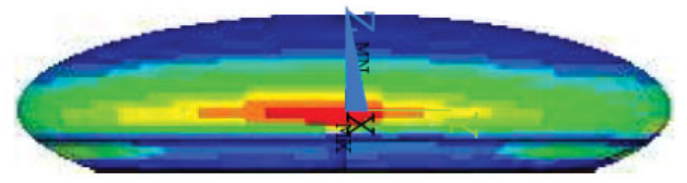

Fig. 3. Membrane (in-plane) inner forces: (a) equator region, where maximum tensile forces develop, (b) diagram of unitary force intensity
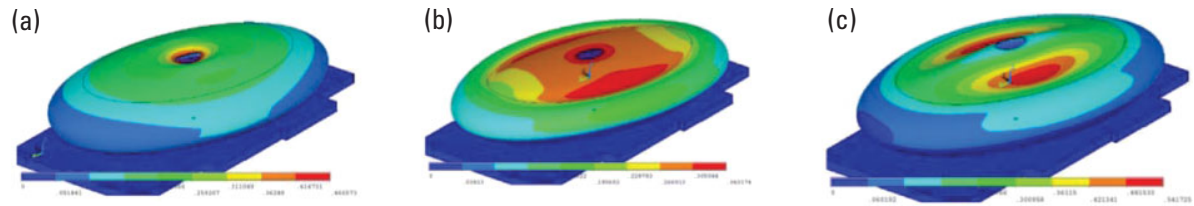

Fig. 4. Deformed shapes at buckling failure: (a) reduced stiffness at zenith opening connection, (b) reduced flexural stiffness at top of post-tensioned region, and (c) overall reduced flexural stiffness

sults with some analytically solved cases such as spheres [14] was also performed in order to check the accuracy and relevance of the FEM results. This approach provided refined solutions but with a means to control them and check the suitability of the results obtained.

\section{Membrane inner forces}

The membrane (in-plane) tensile inner forces were generally moderate or low and could be handled by the minimum reinforcement amount. The most significant exception to this rule was the large tensile forces occurring at the equator of the shell (see Fig. 3). Design was performed to ensure sufficient strength at the ultimate limit state as well as to control crack widths at the serviceability limit state. This required arranging post-tensioning in this region (monostrand tendons). In other parts of the structure it was noted that the delayed strains in the concrete (mainly shrinkage) led to tensile stresses in some regions (particularly at the connection to the concrete basement) which required the provision of sufficient reinforcement for crack control (spacing and crack opening).

\section{Buckling behaviour}

Buckling governed the design of the top region of the shell, with minimum curvature and largest compression forces. Design was performed according to IASS recommendations [9]. In order to determine the buckling behaviour, non-linear analyses were performed considering the initial imperfections, creep strains of concrete, the actual cracked stiffness and the non-linear behaviour [9]. In addition, a sensitivity analysis was performed by assuming large reductions in the stiffness in some selected cases (cracking in selected regions of the shell, local imperfections combined with snow cases or temperature). This modified the buckling modes (see Fig. 4), but with acceptable results in all cases.

\section{Edge forces}

Non-membrane inner forces developed mostly at the concrete basement connection (edge forces due to compatibility). Also, non-membrane inner forces were observed in the post-tensioned region and zenith opening (nevertheless, with a lower intensity than at the basement). 

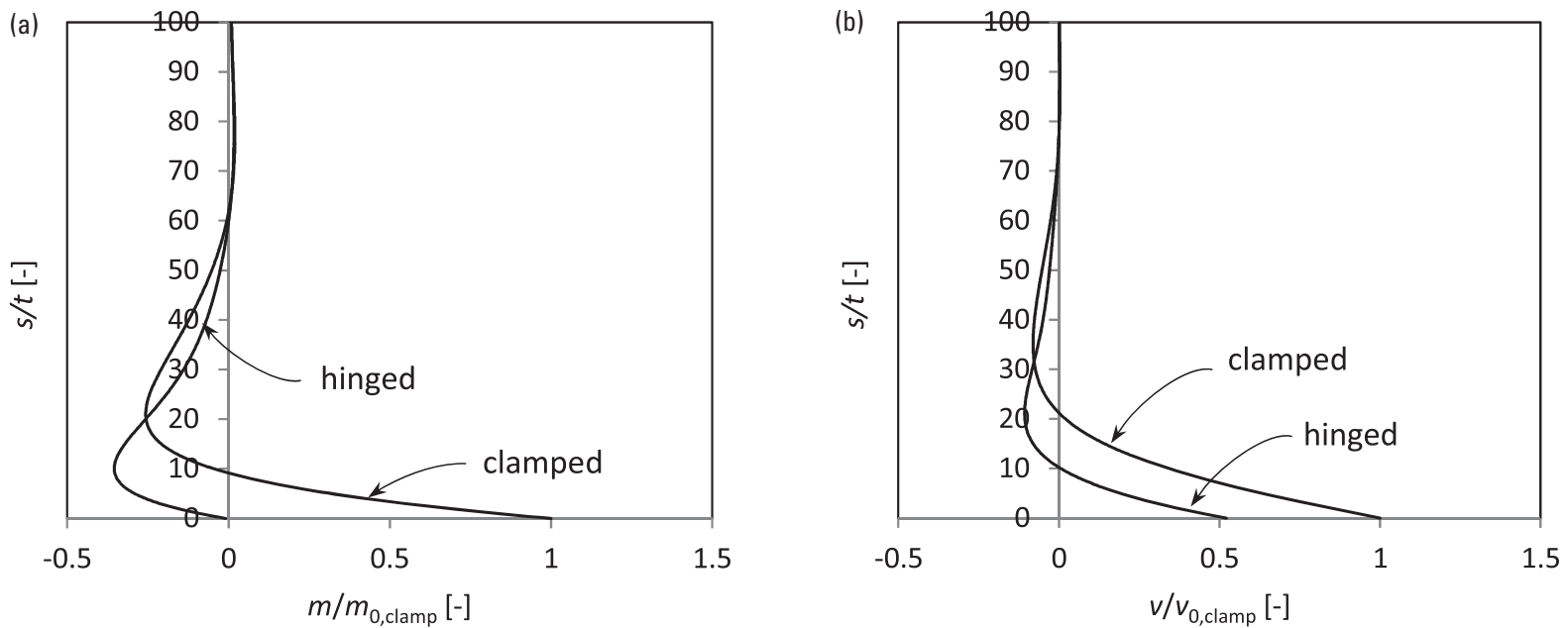

Fig. 5. Comparison of non-membrane forces in vertical (radial) direction (normalized by maximum forces for a clamped case) as a function of the distance to the clamped edge ( $s$ normalized by thickness of slab): (a) bending moments, and (b) shear forces
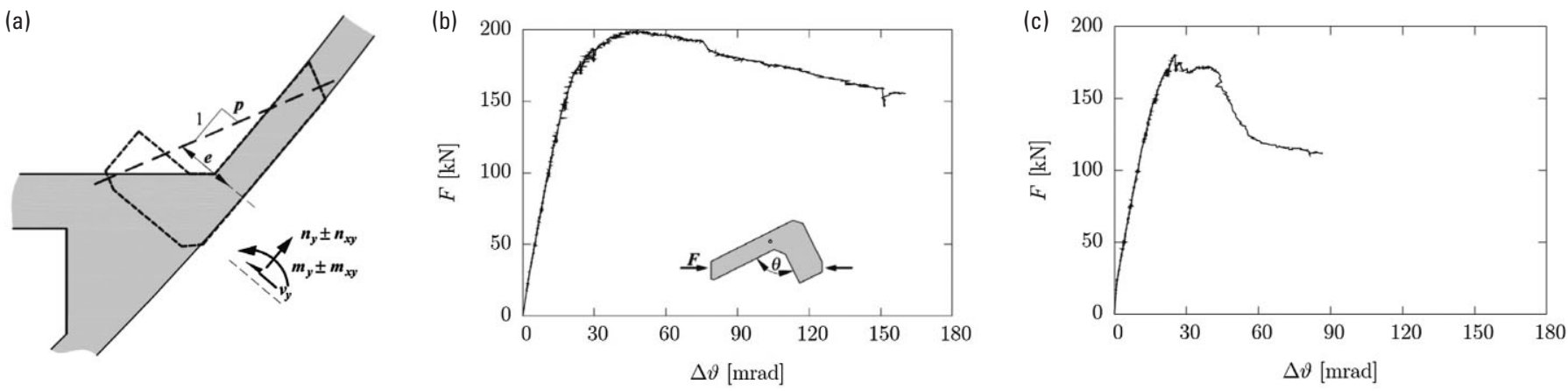

Fig. 6. Shear and bending forces at the connection to the concrete basement: (a) location of theoretical thrust line, (b) behaviour of specimen tested with shear studs, and (c) behaviour of specimen tested without shear studs

The edge forces (bending and shear) typically appear at the boundaries of a shell and are well described in the scientific literature [14]. Both forces can be calculated on the basis of the shell geometry as

$v_{y}=v_{y, 0} \cdot \exp \left(-\lambda_{v} s\right) \cdot \cos \left(\omega_{v} s\right)$

$m_{y}=m_{y, 0} \cdot \exp \left(-\lambda_{m} s\right) \cdot \cos \left(\omega_{m} s\right)$

where

$v_{y}, m_{y}$

unitary shear forces and bending moments at a distance $s$ (perpendicular to the edge direction)

$v_{y, 0}, m_{y, 0} \quad$ unitary shear forces and bending moments at the clamped edge

$\lambda_{v}, \lambda_{m}, \lambda_{v}, \lambda_{m}$ parameters depending on geometry of shell [14] (radius of curvature, thickness, Poisson's coefficient, clamping conditions)

Both formulas lead to an exponential decay of the edge forces modulated by a harmonic function. For the present shell, the influence of the edge forces was almost negligible at a distance $>40$ times the thickness of the shell (see Fig. 5). Accounting for the various imposed strains and load cases, the bending moments and shear forces at the free edges could act with both positive or negative values.
The significance of the edge forces of the boundary conditions should also be noted. For clamped edges, a bending moment appears $\left(m_{y, 0, \text { clamp }}\right)$, which becomes zero for a hinged shell at the edge line, but with a maximum thereafter (with lowest absolute value anyway). Also, with respect to the shear force, a shell supported on a clamped edge exhibits a maximum shear force (at the supported edge, $\left.v_{y, 0, \text { clamp }}\right)$ double that of a hinged shell at the edge line $\left(v_{y, 0, \text { hinged }}\right)$. Fig. 5 plots the normalized inner forces in the region near the basement for two cases. The differences allow an appreciation of how the boundary conditions and deformation capacity influence these forces.

Different strategies are usually followed to provide suitable control of the edge forces. The first one consists of increasing the thickness of the shell locally so that the thrust line can be better accommodated (an analogous approach to that followed for stress ribbons [15]). Alternatively, the reinforcement can be designed at the serviceability limit state accounting for suitable crack control and at the ultimate limit state assuming a plastic redistribution of internal forces (plastic hinge, see Fig. 5, solution between clamped and hinged structures). This latter solution requires a certain level of deformation capacity in the edge region which is influenced by shear forces [16].

For the present shell, the second strategy was adopted to account for architectural and functional needs. The 
solution selected was tested in the laboratory, see Fig. 6. Transverse reinforcement was provided (an amount equal to $0.5 \%$ of the concrete transverse surface) allowing sufficient strength with a large deformation capacity (Fig. 6b). This was instrumental and led to behaviour significantly better than that of a reference control specimen (Fig. 6c) tested without shear studs, which failed at a lower strength but most significantly with a quite limited deformation capacity.

\section{Construction of the shell}

Formwork was placed over timber falsework, Fig. 7a. The formwork was composed of panels bent in situ and screwed in their corresponding positions (Fig. 7b). Reinforcement was then placed and concrete was sprayed or poured in situ (Figs. 7c, 7d). Placing the reinforcement and concreting the shell took about three months in total.

Once concreting was finished, decentering of the shell was performed. This is probably the most critical phase, and in some cases has led shells collapsing [17]. For the present shell, the work was performed in a number of phases in order to avoid decentering being the governing design situation. Firstly, half of the post-tensioning force was applied (one out of two tendons post-tensioned). Then, the timber falsework in contact with the post-ten- sioned zone was removed, followed by the post-tensioning of all tendons. This operation ensured correct post-tensioning transfer to the concrete. Finally, the vertical struts of the falsework supporting the top region of the shell were gradually released, leading to complete decentering of the structure. Measured deflections were recorded during the process and were in good agreement with predicted values. Some pictures of the completed work can be seen in Fig. 8.

The cost of the concrete structure was $49 \%$ for falsework and formwork, $21 \%$ for ordinary reinforcement, $5 \%$ for post-tensioning, $24 \%$ for sprayed concrete and 1\% for poured in situ concrete. This reveals the relatively large cost of falsework and formwork for this type of structure, and points to the need for future research on more efficient techniques.

\section{Conclusions}

This paper has provided a summary of the most relevant aspects related to the design and construction of a concrete shell built in Chiasso, Switzerland. Its main conclusions are:

- Concrete shells are efficient structures and can be used as durable solutions for roofs or for covering large spaces.
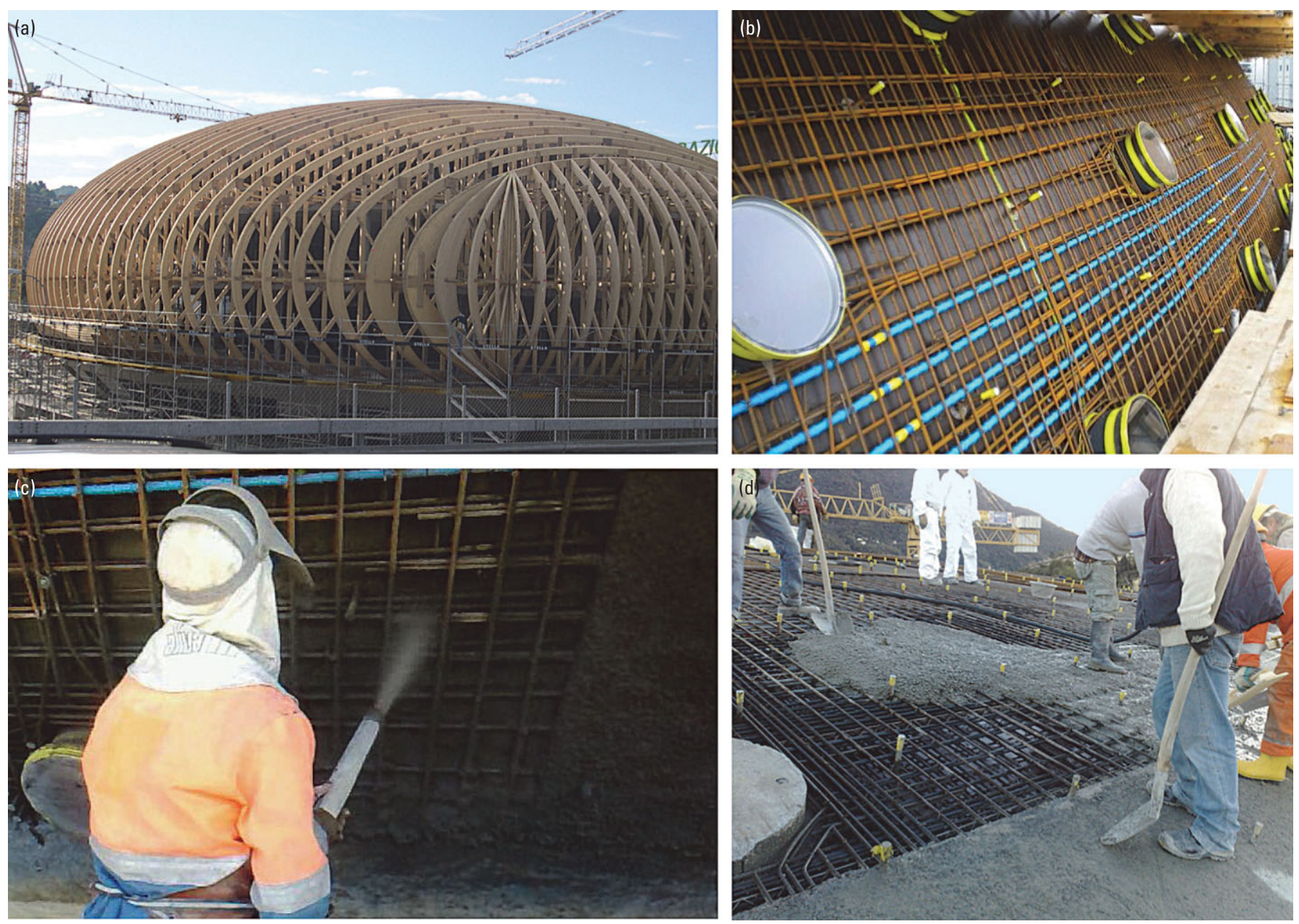

Fig. 7. Construction of shell: (a) temporary falsework, (b) placing of prestressing tendons, (c) spraying of concrete, and (d) pouring of concrete 

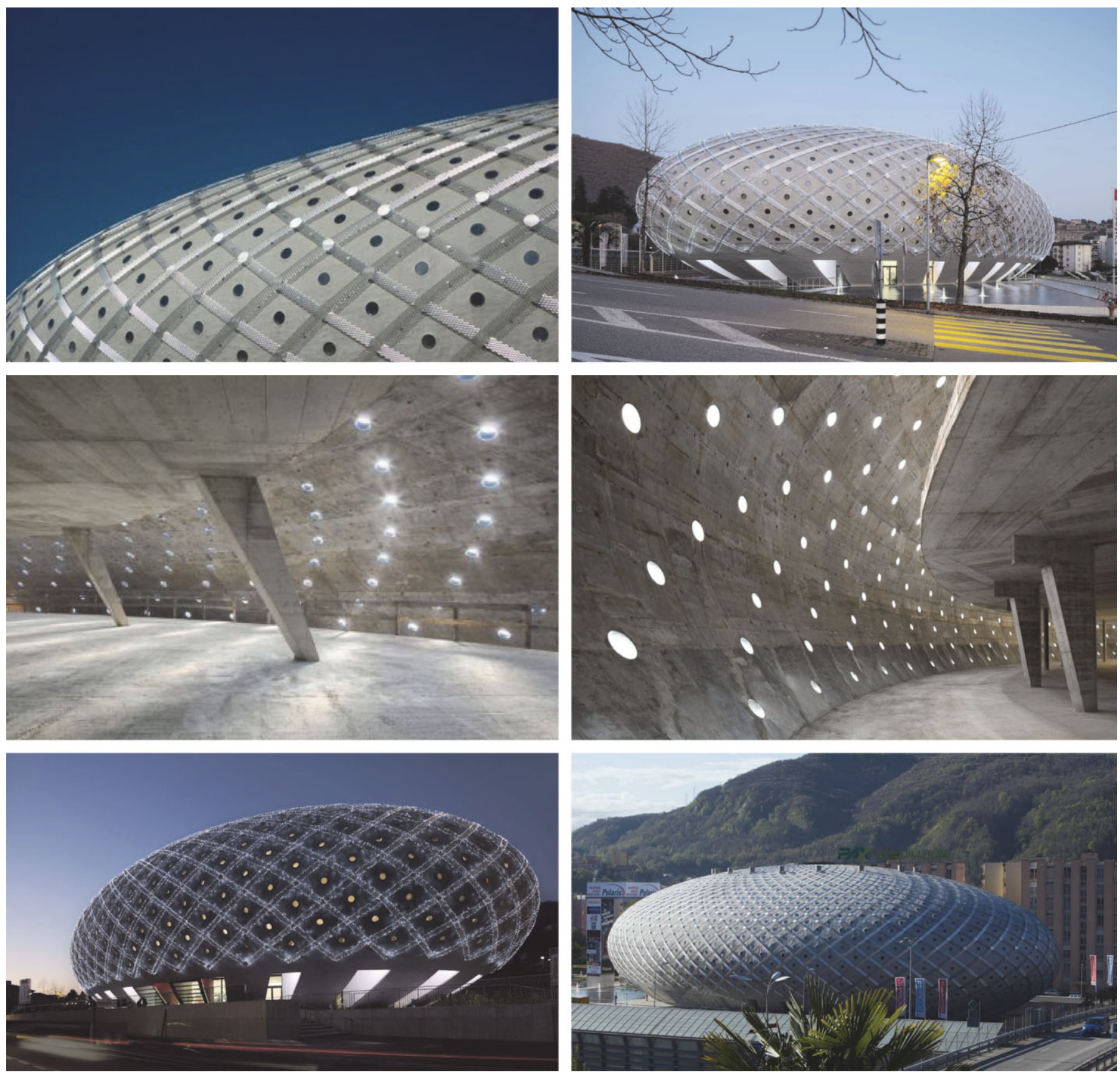

Fig. 8. Completed structure

- Concrete shells can be built with limited thicknesses, thus maximizing the space inside them. This fact also permits the amount of material and energy in their construction to be minimized, thus contributing to a sustainable construction approach.

- The design of concrete shells can be governed by aspects that are not always critical in other types of concrete structure, i.e. membrane forces, second-order effects and edge forces (for compatibility reasons), which are potentially governing criteria in different regions of the shell.

- Research and innovation are still required for formwork and falsework. Traditional approaches lead to good results in terms of shape and quality, but double-curvature surfaces lead potentially to excessively complicated (and expensive) systems.
- Design for buckling of concrete shell structures is a complex topic and is not suitably covered by codes of practice. A review and update of such design provisions should help and encourage designers in the use of concrete shell structures.

\section{Credits}

Structural design and engineering: Aurelio Muttoni, Franco Lurati, Miguel Fernández Ruiz (Mendrisio and Lausanne, Switzerland)

Architecture: Elio Ostinelli (Chiasso, Switzerland) Client: Centro Ovale 1 SA, (Chiasso, Switzerland) Contractor: Muttoni SA, (Bellinzona, Switzerland) Cost: SFr 5,300,000 (VAT and design costs included) 


\section{References}

1. Arenas de Pablo, J. J.: Bridges (in Spanish: Caminos en el aire: los puentes). Colegio de ingenieros de Caminos, Canales y Puertos, Madrid, 2 vols., 2002.

2. Boothby, T. E.: Analysis of masonry arches and vaults. Prog. Struct. Engng. Mater., vol. 3, 2001, pp. 246-256.

3. Boyd, T. D.: The Arch and the Vault in Greek Architecture American Journal of Archaeology, vol. 82, No. 1, 1978, pp. 83-100.

4. Heyman, J.: The Stone Skeleton: structural engineering of masonry architecture. Cambridge University Press, 1995.

5. Muttoni, A.: The art of Structures - an introduction to the functioning of structures in architecture. EPFL Press, Lausanne, Switzerland, 2011.

6. Cassinello, P., Schlaich, M., Torroja, J. A.: Félix Candela. In memoriam (1910-97). From thin concrete shells to the 21st century's lightweight structures (in Spanish: Félix Candela. En memoria (1910-1997). Del cascarón de hormigón a las estructuras ligeras del s. XXI). Informes de la Construcción, vol. 62, No. 519, 2010, pp. 5-26.

7. Chilton, J., Isler, H.: Heinz Isler: The engineer's contribution to contemporary architecture. RIBA Publications/Thomas Telford, 2000, pp. 20-29.

8. Kotnik, T., Schwartz, J.: The Architecture of Heinz Isler. Journal of the International Association for Shell \& Spatial Structures, vol. 52, No. 3, 2011, pp. 185-190.

9. IASS (International Association for Shell \& Spatial Structures), Working Group No. 5: Recommendations for reinforced concrete shells and folded plates. Madrid, Spain, 1979.

10. Espin, A.T: : Optimal design of shape and reinforcement in concrete shells (in Spanish: Diseño óptimo de forma y armado de láminas de hormigón). $\mathrm{PhD}$ thesis, Universidad Politécnica de Cartagena - Departamento de estructuras y construcción, Spain, 2007.

11. Mungan, I.: A conceptual approach to shell buckling with emphasis on reinforced concrete shells. In: Proc. of International Association for Shell \& Spatial Structures (IASS), symposium, 2009, Valencia, pp. 39-50.

12. Muttoni, A., Burdet, O., Hars, E.: Effect of Duct Type on the Shear Strength of Thin Webs. ACI Structural Journal, Farmington Hills, USA, 2006, pp. 729-735.

13. Fernández Ruiz, M., Muttoni, A.: Shear strength of thinwebbed post-tensioned beams. American Concrete Institute, Structural Journal, vol. 105, No. 3, 2008, pp. 308-317.

14. Timoshenko, S., Woinowsky-Krieger, S.: Theory of plates and shells, 2nd ed., McGraw-Hill, 1959.

15. Schlaich, J., Engelsmann, S.: Stress Ribbon Concrete Bridges, Structural Engineering International, 1996, pp. 271-274.

16. Vaz Rodrigues, R., Muttoni, A., Fernández Ruiz, M.: Influence of shear on the rotation capacity of R/C plastic hinges. American Concrete Institute, Structural Journal, vol. 107, No. 5, 2010, pp. 516-525.

17. Garlock, M., Billington, D.: Félix Candela. Engineer, Builder, Structural Artist. Yale University Press, New Haven, CT, 2008.
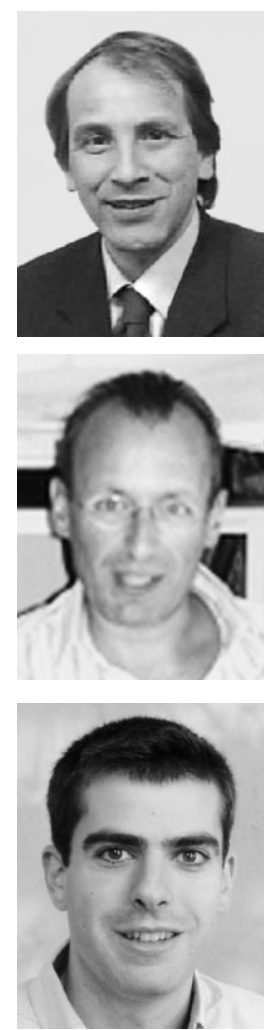

Aurelio Muttoni

Muttoni \& Fernández, ic SA

Route du Bois 17, CH-1024

Lausanne, Switzerland aurelio.muttoni@mfic.ch

Franco Lurati

Lurati Muttoni Partner SA

Via Moree 3, CH-6850

Mendrisio, Switzerland franco.lurati@Impartner.ch

Miguel Fernández Ruiz Muttoni \& Fernández, ic SA

Route du Bois 17, CH-1024

Lausanne, Switzerland

miguel.fernandezruiz@mfic.ch 